\title{
Patients Typing Their Own Visit Agendas Into an Elec- tronic Medical Record: Pilot in a Safety-Net Clinic
}

McHale O. Anderson, $B S^{1}$

Sara L. Jackson, MD, MPH

Natalia V. Oster, MPH

Sue Peacock, MS ${ }^{1}$

Janice D. Walker, RN, $M B A^{2}$

Galen Y. Chen ${ }^{1}$

Joann G. Elmore, $M D, M P H^{1}$

${ }^{1}$ Department of Medicine, University of Washington School of Medicine, Seattle, Washington

${ }^{2}$ Beth Israel Deaconess Medical Center, Harvard Medical School, Boston, Massachusetts

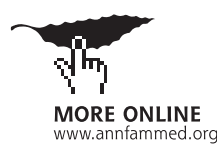

Conflicts of interest: authors report none.

\section{CORRESPONDING AUTHOR}

Joann G. Elmore, MD, MPH

University of Washington School of Medicine

Harborview Medical Center

Department of Internal Medicine

Box 359780, 325 9th Avenue

Seattle, WA 98104

jelmore@uw.edu

\begin{abstract}
Collaborative visit agenda setting between patient and doctor is recommended. We assessed the feasibility, acceptability, and utility of patients attending a large primary care safety-net clinic typing their agendas into the electronic visit note before seeing their clinicians. One hundred and one patients and their 28 clinicians completed post-visit surveys. Patients and clinicians agreed that the agendas improved patient-clinician communication (patients 79\%, clinician 74\%), and wanted to continue having patients type agendas in the future $(73 \%, 82 \%)$. Enabling patients to type visit agendas may enhance care by engaging patients and giving clinicians an efficient way to prioritize patients' concerns.
\end{abstract}

Ann Fam Med 2017;15:158-161. https://doi.org/10.1370/afm.2036.

\section{INTRODUCTION}

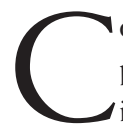
ollaborative agenda setting is a communication skill that helps patients identify concerns early in the clinic visit, ${ }^{1,2}$ possibly diminishing the number of "Oh, by the way" items at the end of visits, ${ }^{3}$ and increasing patient satisfaction. ${ }^{4}$ Agenda setting, however, is often limited by time constraints. ${ }^{4}$

Electronic medical records (EMRs) offer patients access to their medical data, including doctors' notes, ${ }^{5}$ and have the capability to facilitate increased patient involvement in their health care and also contribute to their health data. OpenNotes is a national initiative, not a software program, that invites patients to review their visit notes written by their doctors, nurses, or other clinicians. Existing OpenNotes research shows enthusiasm among both patients and clinicians, ${ }^{6}$ but this is the first OpenNotes study of cogeneration of clinic notes.

Allowing patients to type their agenda into their clinic note before a visit may facilitate communication of health concerns. This article reports a pilot study of feasibility and patient and clinician perceptions of patient-typed visit agendas among a vulnerable patient population at a safety-net clinic.

\section{METHODS}

This study was approved by the University of Washington Institutional Review Board. All patients and clinicians provided informed consent.

\section{Study Population}

Harborview Medical Center (HMC) is a safety-net county hospital in Seattle, Washington caring for the region's most vulnerable patients. We recruited patients and clinicians between June 9 and July 22, 2015 from the HMC Adult Medicine Clinic, a 67-clinician (attending physicians, residents, and advanced practice registered nurses) primary care clinic serving approximately 5,000 patients annually.

We invited a convenience sample of primary care clinicians present in clinic when the research assistant (M.A.) was available. Participating clinicians' patients were recruited via telephone the night before their 
appointment and asked to arrive 30 minutes early or were approached by the receptionist if they had not been reached by phone but still arrived early. Patients younger than 18 years of age, unable to read or write in English, or uncomfortable typing on a computer were ineligible. The research assistant met patients in the waiting room, provided them with a laptop computer with the clinic's EMR interface, and let them type their agenda. The patient typed the agenda in the clinician's "progress notes" field under the research assistant's name with the heading, "The following was typed by the patient as part of a pilot study on patient written visit agendas." Participating clinicians reviewed the agenda before or upon entering the patient's exam room, and the patient's agenda remained in the notes section of the permanent visit record, adjacent to the physician's note, in the EMR. Patients and clinicians were offered gift cards ( $\$ 10$ and $\$ 20$, respectively) to participate and were surveyed after the visit about their experiences.

\section{Patient and Clinician Surveys}

The patient survey queried demographic characteristics, self-reported health, and perceptions of the experience, using a 5-point Likert scale (strongly disagree, disagree, neutral, agree, strongly agree). Clinicians completed a brief survey after each visit asking if the agenda: (1) gave them an improved understanding of the patient's health concerns, and (2) was helpful. Clinicians completed an additional survey at the study's conclusion soliciting age, sex, role in clinic, and perceptions of agendas that mirrored the patient survey. The research assistant also collected time spent typing agendas, number of words typed, and the clinician's billed visit diagnoses and level of service. Surveys are available in the Supplemental Appendix, available at http:// www.AnnFamMed.org/content/15/2/158/suppl/DC1/.

\section{Data Analysis}

Descriptive statistics characterized patient and clinician demographics and perceptions of the agendas, and agenda characteristics such as length and typing time.

\section{RESULTS}

Of 209 invited patients, 26 (12\%) declined and 54 (26\%) were not eligible. Ineligible patients included 35 uncomfortable typing on a computer, 9 who could not read or write in English, and 10 with difficulty both typing and reading/writing. Of the 129 remaining patients, $17 \mathrm{did}$ not come to their appointment or arrived late, 112 typed an agenda, and 11 left before the post-visit survey, leaving 101 patient participants.

Characteristics of this convenience sample (Table 1) are relatively representative of this clinic's patients,
Table 1. Characteristics of Patients, Clinicians, and Visit Agendas

\begin{tabular}{|c|c|c|}
\hline Patient Characteristic $(n=101)$ & N (\%) & \\
\hline \multicolumn{3}{|l|}{ Age } \\
\hline $18-49$ & $28(28 \%)$ & \\
\hline $50-59$ & $31(31 \%)$ & \\
\hline $60-69$ & $33(33 \%)$ & \\
\hline$\geq 70$ & $9(9 \%)$ & \\
\hline \multicolumn{3}{|l|}{ Sex } \\
\hline Male & $57(56 \%)$ & \\
\hline Female & $44(44 \%)$ & \\
\hline \multicolumn{3}{|l|}{ Education } \\
\hline High school or less & $32(32 \%)$ & \\
\hline Some college & $44(44 \%)$ & \\
\hline 4 year college degree or more & $25(25 \%)$ & \\
\hline \multicolumn{3}{|l|}{ Race } \\
\hline White & $56(55 \%)$ & \\
\hline Black & $31(31 \%)$ & \\
\hline Multi-racial/other & $14(14 \%)$ & \\
\hline \multicolumn{3}{|l|}{ Employment $^{\mathrm{a}}$} \\
\hline Employed/self-employed/homemaker & $28(28 \%)$ & \\
\hline Retired & $32(32 \%)$ & \\
\hline Unemployed/unable to work & $40(40 \%)$ & \\
\hline \multicolumn{3}{|l|}{ Self-reported health } \\
\hline Poor & $9(9 \%)$ & \\
\hline Fair & $23(23 \%)$ & \\
\hline Good & $42(42 \%)$ & \\
\hline Very good & $22(22 \%)$ & \\
\hline Excellent & $5(5 \%)$ & \\
\hline \multicolumn{3}{|l|}{ Patient diagnosis ${ }^{b}$} \\
\hline Pain & $36(36 \%)$ & \\
\hline Diabetes & $31(31 \%)$ & \\
\hline HTN & $30(30 \%)$ & \\
\hline Depression & $18(18 \%)$ & \\
\hline Anxiety/Panic & $12(12 \%)$ & \\
\hline \multicolumn{3}{|c|}{$\begin{array}{l}\text { Clinician-documented level of service } \\
\text { (evaluation and management codes) } \text { a,c }^{\text {a }}\end{array}$} \\
\hline 2 & $1(1 \%)$ & \\
\hline 3 & $34(34 \%)$ & \\
\hline 4 & $56(56 \%)$ & \\
\hline \multirow[t]{2}{*}{5} & $8(8 \%)$ & \\
\hline & & (continues) \\
\hline \multicolumn{3}{|c|}{$\begin{array}{l}\text { a One respondent did not provide employment information. Level of service } \\
\text { was unattainable for } 2 \text { respondents due to technical issues. Data on time to } \\
\text { type agenda was not available for } 4 \text { patients. } \\
\text { b Most common diagnoses; could have more than } 1 \text { diagnosis per visit. } \\
\text { ' Evaluation and management codes range from low complexity visit (Level 2) } \\
\text { to high complexity (Level 5). }\end{array}$} \\
\hline
\end{tabular}

and age and diagnoses were not statistically different between those who participated and those who chose not to participate (data not shown). Agendas were brief, $83 \%$ of patients typed for $<10$ minutes, and $80 \%$ typed $<60$ words. Table 2 shows an example patienttyped agenda and responses from the patient and clinician follow-up surveys. 
Table 1. Characteristics of Patients, Clinicians, and Visit Agendas (continued)

\begin{tabular}{lr}
\hline Clinician Characteristics (N = 27) & $\mathbf{N}(\%)$ \\
\hline Age (years) & $18(67 \%)$ \\
$<40$ & $9(33 \%)$ \\
$\geq 40$ & \\
Sex & $6(22 \%)$ \\
Male & $21(78 \%)$ \\
Female & \\
Role & $13(48 \%)$ \\
Teaching attending physicians/advanced & \\
$\quad$ registered nurse practitioners & $14(52 \%)$ \\
Residents & $\mathbf{N}(\%)$ \\
Agenda characteristics (N = 101) & \\
\hline $\begin{array}{l}\text { Time (in minutes) to type agenda } \\
<5\end{array}$ & $39(40 \%)$ \\
$5-9$ & $42(43 \%)$ \\
$\geq 10$ & $16(16 \%)$ \\
Number of words typed & \\
$<15$ & $21(21 \%)$ \\
$15-29$ & $30(30 \%)$ \\
$30-59$ & $29(29 \%)$ \\
$\geq 60$ & $21(21 \%)$ \\
\hline
\end{tabular}

Agenda perceptions were strongly positive among both patients and clinicians (Figure 1).

\section{DISCUSSION}

Patients attending a safety-net primary care clinic were interested and able to type their agenda into the EMR visit note. Patients and clinicians felt this improved communication and both expressed interest in patient-written agendas in the future. In this diverse population of patients with complex medical conditions, $28 \%$ employment, and $32 \%$ high school or less education, nearly two-thirds of the patients approached were not limited by lack of English or computer literacy and participated.

Clinicians often cite inadequate visit time as a barrier to relationship development and communication with patients. ${ }^{2,7}$ Interacting with EMRs during patient interviews has also eroded clinicians' ability to connect with patients ${ }^{8}$ and led to clinician dissatisfaction with clinical practice, particularly in primary care. ${ }^{9}$ This pilot study suggests a possible way for the EMR to offset the time and computer barriers to communication. By allowing patients to set agendas before appointments, patients and clinicians can optimize their time together.

The Patient Protection and Affordable Care Act identifies patient activation and engagement as key components of accountable care organizations and patient-centered medical homes. ${ }^{10} \mathrm{~A}$ few studies have addressed electronic portals and patient activation with
Table 2. Example of a Patient-Typed Agenda and Clinician Comment; Examples of Patients' and Clinicians' Responses from the Follow-Up Survey

A. Example of Patient-Typed Agenda and Clinician Response

Patient-typed agenda:

"1. Lumps on my lungs

2. my ankle is not getting better

3. the boot is giving me knee problems"

Clinician's comments on the above patient-typed agenda:

"My patient typed 'lumps on lungs'. This was a pulmonary nodule identified on a CT scan in the ER that I might have missed if he had not put it on his agenda. While the nodule was incidental, the patient was anxious about the finding and I was able to provide reassurance."

B. Examples of Patients' and Clinicians' Responses from the Follow-up Survey

Patients' comments from the follow-up survey

- "Helps me remember what I am being seen for"

- "Gave doctor my information so I wouldn't be nervous and forget"

- "Doctor and I on same page"

- "Made me think about reasons for visit before seeing doctor"

- "New doctor so this was excellent way of getting my feelings across"

Clinicians' comments from the follow-up survey

- "Got time to think about issues ahead of time"

- "Engaged patient to participate more in the visit, he felt 'heard"

promising initial results. ${ }^{11,12}$ In the original OpenNotes study, $59 \%$ to $62 \%$ of patients believed they should be able to comment on their clinic notes. ${ }^{6}$ In our current study, patients accepted the opportunity to directly contribute to their visit notes by typing their visit agendas. Future studies could evaluate the relationships between agenda setting and other contributions to notes, and patient engagement.

This pilot study was limited to a small convenience sample at a single clinic with no comparison group, and the results may not be generalizable to other settings. We provided financial incentives for participants, and a research assistant facilitated the agenda typing process. This study involved a vulnerable patient population $i$ it is also important to note that of those approached, $12 \%$ declined and $26 \%$ were not eligible because they could not type or write in English. Though not available in this study, patient navigators, peer coaches, translators, or audio and touch-screen technologies may be able to address limitations in English or computer literacy, or low vision, hearing, or comprehension. Nevertheless, approximately one-half of our target patients completed the intervention and both patients and clinicians found agenda setting worthwhile. 


\section{Figure 1. Patient $(\mathrm{N}=101)$ and clinician $(\mathrm{N}=27)$ perceptions of patient- written agendas. ${ }^{a}$}

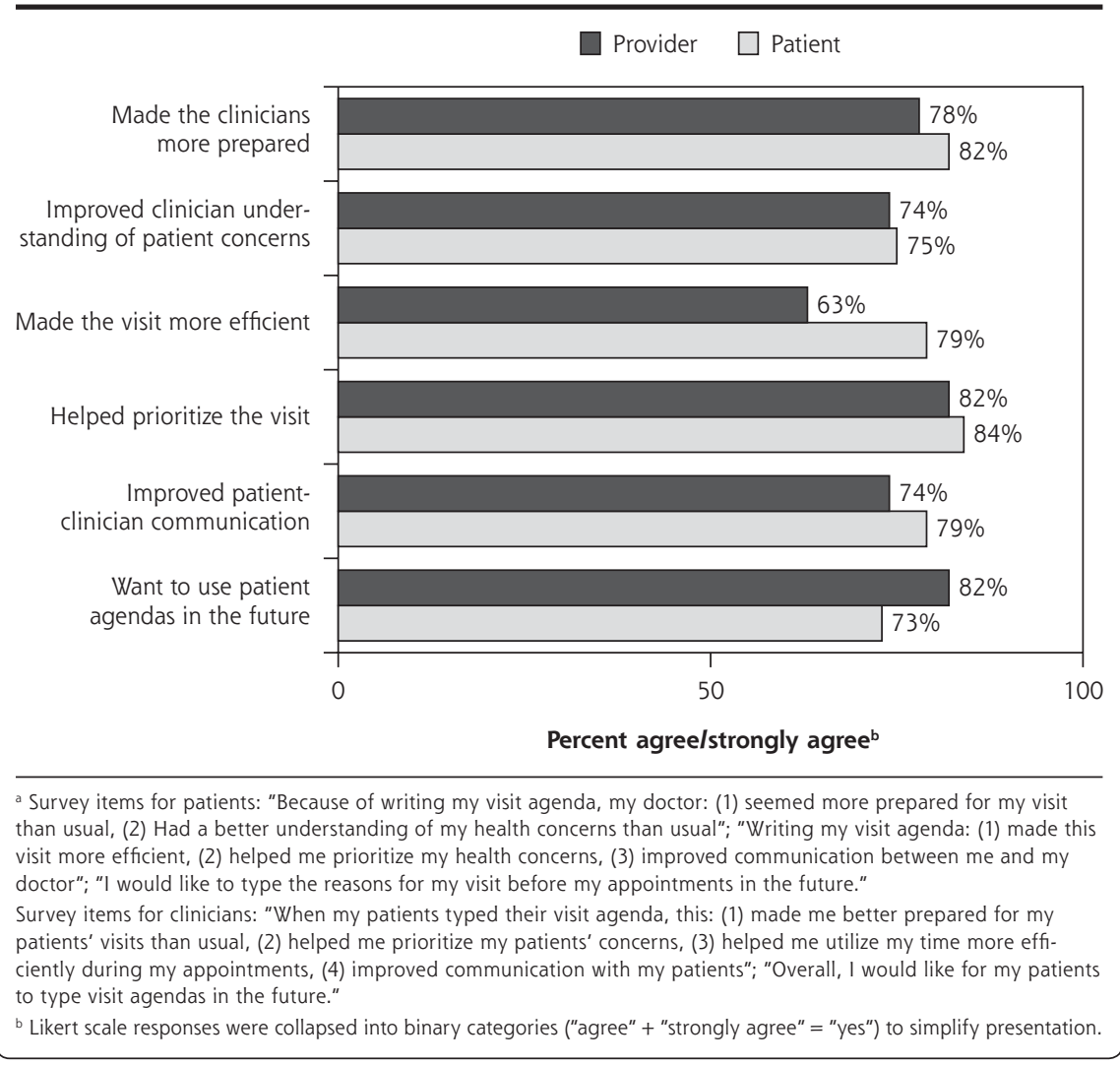

Supplementary materials: Available at http://www.Ann FamMed.org/content/15/2/158/ suppl/DC1/

\section{References}

1. Baker LH, O'connell D, Platt FW. "What else?" Setting the agenda for the clinical interview. Ann Intern Med. 2005;143(10):766-770.

2. Mauksch LB, Dugdale DC, Dodson S, Epstein R. Relationship, communication, and efficiency in the medical encounter: creating a clinical model from a literature review. Arch Intern Med. 2008;168(13):1387-1395.

3. Brock DM, Mauksch LB, Witteborn S, Hummel J, Nagasawa P, Robins LS. Effectiveness of intensive physician training in upfront agenda setting. J Gen Intern Med. 2011;26(11):1317-1323.

4. Rodriguez HP, Anastario MP, Frankel RM, et al. Can teaching agenda-setting skills to physicians improve clinical interaction quality? A controlled intervention. BMC Med Educ. 2008;8(1):3.

5. Walker J, Meltsner M, Delbanco T. US experience with doctors and patients sharing clinical notes. BMJ. 2015;350:g7785.

6. Delbanco T, Walker J, Bell SK, et al. Inviting patients to read their

The patient cogeneration of visit notes, facilitated by new EMR functionality, reflects a shift in the authorship and "ownership" of visit notes. Patientwritten visit agendas could increase the collaborative nature of the clinical encounter between patient and clinician, but require further study, including measurement of patient engagement and health outcomes.

To read or post commentaries in response to this article, see it online at http://www.annfammed.org/content/15/2/158.

Key words: electronic medical records; patient-provider communication; self-management.

Submitted June 21, 2016; submitted, revised, September 28, 2016; accepted October 10, 2016

Previous presentation: These results were presented at the Society of General Internal Medicine (SGIM) annual conference; May 11-14, 2016; Hollywood, Florida.

Acknowledgments: The authors gratefully acknowledge support from The Commonwealth Fund, Robert Wood Johnson Foundation, Gordon and Betty Moore Foundation, Peterson Center on Healthcare, and Cambia Health Foundation, the National Cancer Institute (K05 CA104699; J.E.), and the University of Washington School of Medicine Medical Student Research Training Program (M.A.). doctors' notes: a quasi-experimental study and a look ahead. Ann Intern Med. 2012;157(7):461-470.

7. Dugdale DC, Epstein R, Pantilat SZ. Time and the patient-physician relationship. J Gen Intern Med. 1999;14(Suppl 1):S34-S40.

8. Chen P. An unforeseen complication of electronic medical records. The New York Times. April 22, 2010.

9. Sinsky CA, Beasley JW, Simmons GE, Baron RJ. Electronic health records: design, implementation, and policy for higher-value primary care. Ann Intern Med. 2014;160(10):727-728.

10. Hibbard JH, Greene J. What the evidence shows about patient activation: better health outcomes and care experiences; fewer data on costs. Health Aff (Millwood). 2013;32(2):207-214.

11. Nagykaldi Z, Aspy CB, Chou A, Mold JW. Impact of a Wellness Portal on the delivery of patient-centered preventive care. J Am Board Fam Med. 2012;25(2):158-167.

12. Wagner PJ, Sodomka P, Dias J, et al. Using an Electronic Personal Health Record to Empower Patients with Hypertension. Rockville, MD: Agency for Healthcare Research and Quality; 2011. 